\title{
Evaluation of the most appropriate spatial resolution of input data for assessing the impact of climate change on rice productivity in Japan
}

\author{
Yasushi Ishigooka ${ }^{\mathrm{a}, \dagger}$, Toshihiro HASEgawa ${ }^{\mathrm{b}}$, Tsuneo KuWAGATA ${ }^{\mathrm{a}}$ and Motoki NishimorI ${ }^{\mathrm{a}}$ \\ ${ }^{a}$ Institute for Agro-Environmental Sciences, National Agricultural and Food Research Organization, \\ 3-1-3 Kannondai, Tsukuba, Ibaraki 305-8604, Japan \\ ${ }^{\mathrm{b}}$ Tohoku Agricultural Research Center, National Agricultural and Food Research Organization, \\ 4 Akahira, Shimo-kuriyagawa, Morioka, Iwate 020-0198, Japan
}

\begin{abstract}
Process-based crop growth models are increasingly utilized as an essential tool for assessing the impact of climate change on crop productivity at field, regional, and national scales. The reliability of model predictions depends strongly on the quality of the meteorological data used as inputs. For evaluations over large areas, the spatial resolution of input data affects the calculation results because factors such as elevation differences between the mean for an entire grid cell and the portion of crop land in the grid can introduce a major temperature bias in the input data. In this study, we attempted to identify the most appropriate spatial resolution to support assessment of the impact of climate change on rice productivity in Japan. We used the Hasegawa-Horie rice growth model under the baseline climate conditions (1981 to 2000) and then applied the model to account for temperature increases to 1 and $3{ }^{\circ} \mathrm{C}$ higher than the baseline. First, we calculated the rice yield using inputs at 100-m resolution as the "true value". We then compared the rice yield calculated using inputs at $10-\mathrm{km}$ and $1-\mathrm{km}$ resolutions with the yield calculated using inputs at $100-\mathrm{m}$ resolution. We found that the yield differences were larger with 10-km resolution than with 1-km resolution in areas that had complex terrain, but the differences were small in homogeneous flat areas. Where the terrain is extremely complex, regional mean yields were underestimated by $11.5 \%$ compared with the yield under baseline climatic conditions but were overestimated by $5.4 \%$ at increased temperatures using $10-\mathrm{km}$ resolution. These differences are likely to be a major cause of uncertainty in predicting the impacts of climate change on yield at a regional scale. Spatial resolution of input data, using 10-km resolution did not affect the assessment results when yield is aggregated at a national scale.
\end{abstract}

Key words: Impact assessment, Rice yield, Spatial resolution, Temperature bias, Terrain

\section{Introduction}

To stabilize crop productivity under projected future climate change, it is important to develop effective mitigation and adaptation strategies based on reliable information and develop appropriate impact assessments. Process-based crop growth models are an essential tool to quantify the impact of climate change on crop yield or quality (Hansen and Jones, 2000; Rosenzweig et al., 2014; Hasegawa et al., 2016). Rice is the most important food crop in Japan, so the impact of climate change on rice production or quality has been assessed at national or regional scales using rice growth models (e.g. Horie et al., 1995; Seino, 1997; Yonemura et al., 1998; Hayashi et al., 2001; Iizumi et al., 2006, 2011; Yokozawa et al., 2009; Ishigooka et al., 2017).

In many crop growth models, parameters were optimized using meteorological data observed near the cultivation experiment. Thus, the reliability of the model output depends strongly on the quality of the input meteorological data (Kuwagata et al., 2014). In simulations that evaluate long-term climate change over large areas, the spatial resolution of the input data has been relatively coarse, largely due to limitations caused by calculation times and

\footnotetext{
Received; May 22, 2019

Accepted; November 13, 2019

${ }^{\dagger}$ Corresponding author: isigo@affrc.go.jp

DOI: 10.2480/agrmet.D-19-00021
}

difficulty preparing high-resolution input data for long periods under multiple climate scenarios. If the spatial resolution of the input data is coarser than the scale at which terrain features vary, the data inevitably fail to account for the effects of heterogeneous meteorological or other conditions that arise from factors such as differences in elevation or coastal effects (Hansen and Jones, 2000; Daly, 2006; van Bussel et al., 2016). These variations are likely to be major causes of uncertainty in the model outputs.

Many previous studies focused on the effect of the spatial resolution of meteorological data on simulated crop yields or phenology, and compared the results calculated using data with different spatial resolutions. Some reports showed that differences in the spatial resolution of input data did not influence the results of national-scale assessments because the differences between model's output values of individual grid cells tended to cancel each other out by averaging across large areas (e.g. Olesen et al., 2000; van Bussel et al., 2011; Rezaei et al., 2015). Other reports showed a large effect of the spatial resolution in topographically complex areas, and suggested that high resolution may be required to accurately evaluate the characteristics of the spatial distribution of factors such as temperature at a regional scale (e.g. Kim et al., 2015; Rezaei et al., 2015; Zhao et al., 2015).

In most previous studies that attempted to evaluate the effect of spatial resolution on impact assessments, the target was limited to upland crops in Europe (e.g. Olesen et al., 2000; van Bussel et al., 2011; Rezaei et al., 2015; Zhao et al., 2015). Other areas with 
different agricultural ecosystems and climates have rarely been studied; the only previous study we found in our literature review was the study by Kim et al. (2015), which focused on the effect of the spatial resolution of the inputs on a rice yield simulation in Korea. In general, crop land is distributed in areas with a low elevation; thus, mean temperature in a grid cell with a low resolution (i.e. coarse resolution) spatial resolution located in areas with complex topography may be lower than the temperature on the crop cultivated field within the grid cell. These temperature bias may be stronger in rice paddy fields, because the paddy fields are generally developed over lower land compared with the upland crop in order to be flooded constantly during the rice cultivation period.

In this study, we attempted to elucidate the most appropriate spatial resolution to predict the impact of climate change on rice productivity in Japan. To do so, we compared the rice yields simulated by a process-based rice simulation model using input data with different spatial resolutions $(1 \mathrm{~km} \times 1 \mathrm{~km}$ and $10 \mathrm{~km} \times$ $10 \mathrm{~km}$, approximately; hereafter, the " $1-\mathrm{km}$ resolution" and " $10-\mathrm{km}$ resolution", respectively) with those obtained from the same model using high-resolution input data $(100 \mathrm{~m} \times 100 \mathrm{~m}$, approximately; hereafter, "100-m resolution"). The input meteorological data were obtained for the period from 1981 to 2000. To investigate the effect of different spatial resolution on the yield change due to the temperature increase, we also prepared a dataset in which the temperature increased by $3{ }^{\circ} \mathrm{C}$ (see section 2.4 ).

\section{Materials and methods}

\subsection{Study area}

The study area covered all of Japan except for some small islands that had no paddy fields; it therefore ranged from latitude $24^{\circ} \mathrm{N}$ to $46^{\circ} \mathrm{N}$ and from longitude $122^{\circ} \mathrm{E}$ to $146^{\circ} \mathrm{E}$ (Fig. 1). In 2017, paddy fields in Japan covered $24180 \mathrm{~km}^{2}$, which accounts for $54.4 \%$ of the total area of arable land $\left(44440 \mathrm{~km}^{2}\right)$ and $6.4 \%$ of Japan's total land area $\left(378000 \mathrm{~km}^{2}\right)$ (MAFF, 2018). Most of Japan's rice is cultivated in irrigated paddy fields, which cover $14650 \mathrm{~km}^{2}$ (MAFF, 2018). The paddy fields are distributed

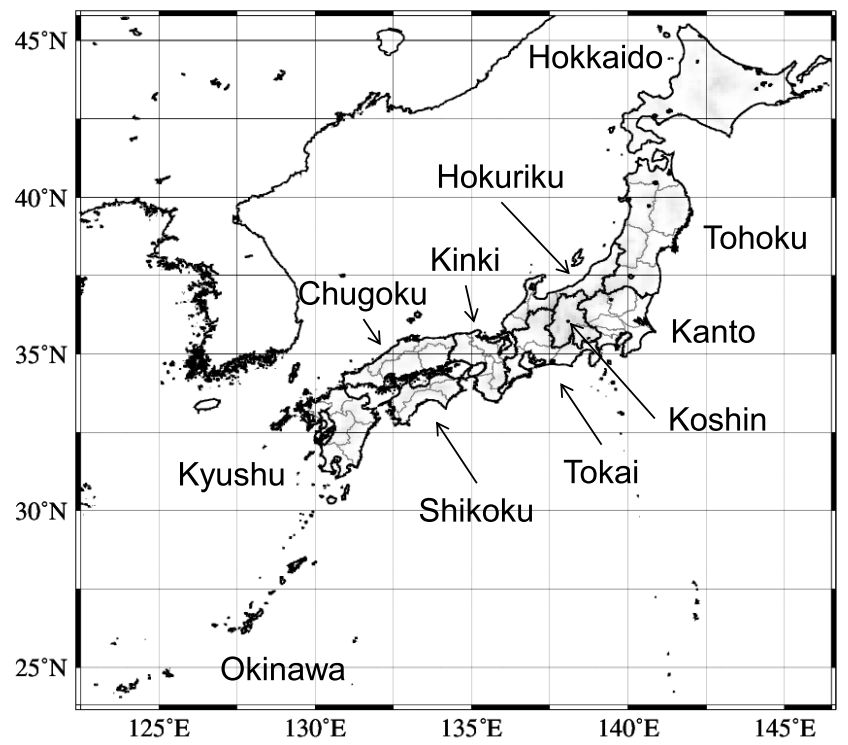

Fig. 1. The study area in Japan. Thick black lines are regional boundaries, and thin gray lines show prefecture boundaries. mainly in lowland areas such as plains and the bottoms of basins or valleys in parts of Japan where climatic conditions are suitable for rice cultivation; the northern limit is on Hokkaido Island, at $44^{\circ} 45^{\prime} \mathrm{N}, 141^{\circ} 52^{\prime} \mathrm{E}$, and the highest elevation is $1260 \mathrm{~m}$ a.s.1., in Nagano Prefecture, in the central part of Honshu Island.

\subsection{Crop model}

We used the Hasegawa-Horie model (hereafter, "H/H model") that was originally developed by Hasegawa and Horie (1997) and modified by Fukui et al. (2015) and Yoshida et al. (2015), to estimate rice phenological development and yield. The $\mathrm{H} / \mathrm{H}$ model can be used for Japan's 15 major cultivars and has been validated and applied successfully for large-scale assessment of the impacts of climate change on rice productivity in Japan (Yoshida et al., 2015; Ishigooka et al., 2017). The $\mathrm{H} / \mathrm{H}$ model uses the following input data: daily meteorological data (maximum and minimum temperatures, solar radiation, relative humidity, and wind speed), geographical data (latitude and elevation), atmospheric $\mathrm{CO}_{2}$ concentration, and rice cultivation management information (cultivars, transplanting date, and amount of nitrogen fertilizer).

In the $\mathrm{H} / \mathrm{H}$ model, the phenological development of each cultivar is quantified using a developmental index that equals the increment in the daily developmental rate calculated using the daily mean temperature and day-length. The yield is calculated by multiplying the biomass by the harvest index. The biomass is calculated as the accumulation of the photoassimilates produced by photosynthesis. The harvest index is calculated by modifying the potential harvest index to account for three adjustment factors: spikelet sterility caused by low temperature, that caused by high temperature, and the delay of maturity caused by insufficient temperature. Therefore, the outputs from this model are highly sensitive to temperatures during the cultivation period.

The $\mathrm{H} / \mathrm{H}$ model was described in detail by Hasegawa and Horie (1997), Fukui et al. (2015), and Yoshida et al. (2015). Application of the $\mathrm{H} / \mathrm{H}$ model for large-area simulation of rice yield was described by Ishigooka et al. (2017). Some of the validation results of the model performance had been summarized in Table 2 (phenology estimation) and Fig. 2 (yield estimation) in Ishigooka et al. (2017), which showed that the model can sufficiently reproduce both phenological development and yield formation in the regional scale.

\subsection{Geographical data}

All geographical data used in this study conformed to the Tokyo Datum geographic coordinate system. As the dataset for 100-m spatial resolution for the distribution of paddy fields, we used the "Land Use Fragmented Mesh Data 2006" derived from the dataset of National Land Numerical Information, Geospatial Information Authority of Japan (GSI), which has a resolution of 3" in latitude and $4.5^{\prime \prime}$ in longitude $(100 \mathrm{~m} \times 100 \mathrm{~m}$, approximately; available at: http://nlftp.mlit.go.jp/ksj/gml/datalist/KsjTmplt-L03-b.html). In this data, each grid cell of $100-\mathrm{m}$ resolution is classified into one of 11 land-use categories, including paddy field. Each paddy field cell was aggregated into the corresponding grid cell of $1-\mathrm{km}$ and $10-\mathrm{km}$ resolution by summing the area of paddy fields cells in each resolution of grid cell and calculating the percentage of the areas occupied by the paddy fields.

We obtained a digital elevation model (DEM) of the 100-m 
resolution dataset from the "digital map 50 m grid (elevation)" (Geographical Survey Institute Japan, 1997) by averaging the data in the corresponding grid cells of $100-\mathrm{m}$ resolution. Then, we calculated the mean elevations for entire land-area and paddy-area of $1-\mathrm{km}$ and $10-\mathrm{km}$ resolution by using the $100-\mathrm{m}$ resolution land-use data and the created 100-m resolution DEM.

The transplanting date and the cultivars were derived from the yearly agricultural statistics provided by the Ministry of Agriculture, Forestry and Fisheries, Japan (available at: http://www.maff.go.jp/j/tokei/kouhyou/kensaku/bunya2.html), in which the statistical values are summarized by administrative regions (i.e. region, prefecture, sub-prefectural region). We also calculated the nitrogen fertilizer input by the region using the statistical data (Ishigooka et al., 2017). Because of a lack of information on the spatial distribution of those statistical values within each administrative region, we assumed that the same statistical value was distributed uniformly throughout the administrative region.

\subsection{Meteorological data}

We used the gridded daily meteorological dataset with a $1-\mathrm{km}$ resolution developed by the Institute for Agro-Environmental Sciences, NARO (hereafter, "NIAES Mesh Meteorological Dataset"; Seino, 1993) as inputs for the model. This dataset was created from the daily observed meteorological data obtained from Japan's Automated Meteorological Data Acquisition System (AMeDAS) stations and the monthly climatic data; we used the 30-year average from 1971 to 2000, with a 1-km resolution (Japan Meteorological Agency, 2002), using the distance-weighted interpolation process described by Seino (1993).

The daily maximum and minimum temperatures at $100-\mathrm{m}$ resolution were created as follows. The value from the NIAES Mesh Meteorological Dataset was divided to $100-\mathrm{m}$ resolution, and was then adjusted to account for the elevation difference between the grid cell in the $100-\mathrm{m}$ resolution and the corresponding 1-km grid cell based on the commonly used temperature lapse rate $\left(-0.0065{ }^{\circ} \mathrm{C} \mathrm{m}^{-1}\right)$. Strictly speaking, temperature is affected by more than elevation; other factors such as the local topography (e.g., slope aspect), vegetation, and distance from a body of water also affect temperature. However, we made the simplifying assumption that elevation was the dominant factor that affected temperature within a small spatial extent (i.e., $100 \mathrm{~m}$ ). This simplification is acceptable because the aim of our study was not to calculate rice yield precisely but rather to evaluate the effect of differences in spatial resolution on the simulated rice yield. This agrees with our approach for the other elements of the of 100-m resolution (solar radiation, relative humidity, and wind speed), which were prepared by disaggregating the $1-\mathrm{km}$ data without any adjustments. The meteorological dataset with $10-\mathrm{km}$ resolution was also created using the NIAES Mesh Meteorological Dataset by calculating an arithmetic average of the values with $1-\mathrm{km}$ resolution contained within each grid with a $10-\mathrm{km}$ resolution for all meteorological elements.

The meteorological data were obtained for the period from 1981 to 2000 , which we considered to represent the baseline climate conditions in this study, for all three spatial resolutions. We then created temperature-increase datasets by adding 1,2 , and $3{ }^{\circ} \mathrm{C}$ to the daily maximum and minimum temperatures for the baseline period, but did not change any other elements of the meteorological data.

\subsection{Analytical procedures}

In this study, we implemented the $\mathrm{H} / \mathrm{H}$ model with daily meteorological datasets as inputs for the four temperature levels (baseline plus three increases) for each of the three spatial resolutions described from 1981 to 2000 . We fixed the distribution of the paddy fields to the distribution in 2006, and ignored any land-use change. Likewise, we kept the cultivars and nitrogen inputs for each grid cell fixed at the 2006 levels. Atmospheric $\mathrm{CO}_{2}$ concentration data were obtained from the World Data Center for Greenhouse Gases (available at: http://ds.data.jma.go.jp/gmd/wdcgg/wdcgg.html).

We ran the $\mathrm{H} / \mathrm{H}$ model for all grid cells where the land use was classified as paddy field for the data with $100-\mathrm{m}$ resolution, for all grid cells in which the percentage of the areas occupied by the paddy fields was larger than $1 \%$ of the total land area for the data with $1-\mathrm{km}$ and $10-\mathrm{km}$ resolution.

\section{Results}

\subsection{Elevation difference between entire grid cell and the paddy fields}

We first calculated the spatial distribution of the differences between the mean elevation for all internal sub-grid cells (100-m resolution) and the mean elevation for internal sub-grid cells with paddy-field, at 10-km resolution (Fig. 2a) and at 1-km resolution (Fig. 2b). Note that the values are positive if the mean elevation for all grid cells is larger than the mean elevation for internal paddy-field cells. At 10-km resolution, large elevation differences $(>200 \mathrm{~m})$ were distributed widely in and around mountainous areas, especially in the central part of Japan, whereas the elevation differences were almost zero in some plains in the central and eastern parts of Japan (Fig. 2a). At 1-km resolution, in contrast, the elevation differences were generally not large, although relatively large differences $(>100 \mathrm{~m})$ were distributed in mountainous areas, especially in the western part of Japan (Fig. 2b). Regardless of resolution, the elevation differences are positive in almost all grids, which is because the paddy field tend to be opened to areas lower than surrounding areas.

To quantify the areal characteristics of the elevation differences for the two spatial resolutions, we averaged the elevation differences within each prefecture (a level of Japanese local government that divides the country into 47 districts). Figs. $3 \mathrm{a}$ and $3 \mathrm{~b}$ show the results at $10-\mathrm{km}$ and $1-\mathrm{km}$ resolutions, respectively. Overall, the mean elevation differences for $10-\mathrm{km}$ resolution were considerably larger than those for $1-\mathrm{km}$ resolution. The mean elevation difference ranged from 8.0 to $202.2 \mathrm{~m}$ (with a national mean of $64.9 \mathrm{~m}$ ) for $10-\mathrm{km}$ resolution, but ranged from 1.3 to $35.7 \mathrm{~m}$ (with a national mean of $12.1 \mathrm{~m}$ ) for $1-\mathrm{km}$ resolution; in all prefectures, the elevation differences at $10-\mathrm{km}$ resolution were larger than those at $1-\mathrm{km}$ resolution.

\subsection{Comparison of simulated yields}

We supplied the $\mathrm{H} / \mathrm{H}$ model with input data at the three spatial resolutions (100-m, 1-km, and 10-km resolutions) for the 


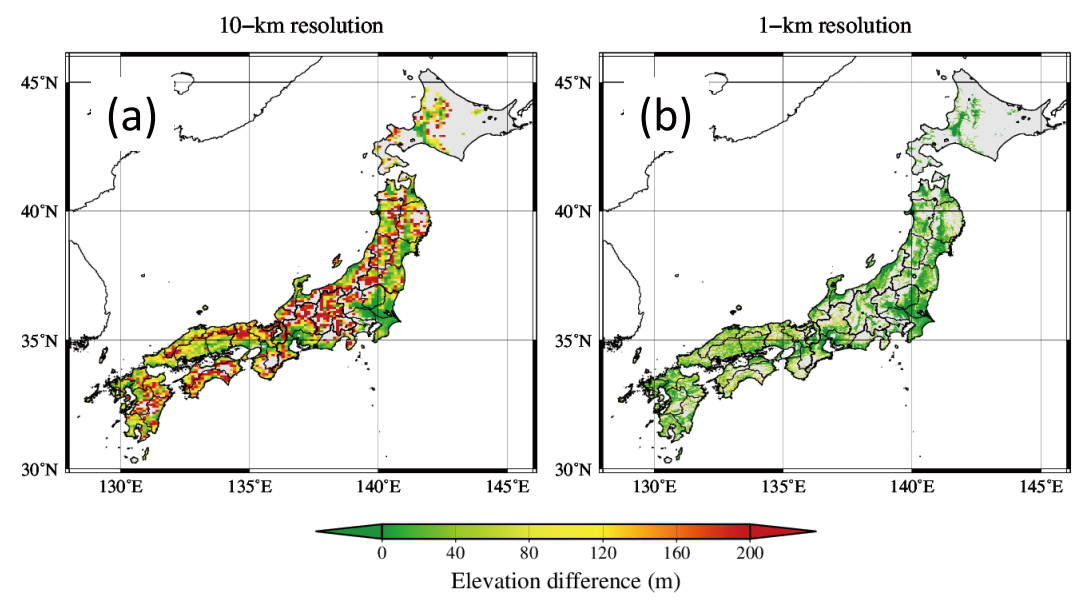

Fig. 2. The spatial distribution of the differences between the elevation of the grid cell that was calculated as the mean elevation for all internal sub-grid cells (100-m resolution) and the mean elevation for internal sub-grid cells with paddy-field, at (a) $10-\mathrm{km}$ resolution and (b) 1-km resolution. Values are positive if the elevation of the grid cell is larger than the mean elevation for internal paddy-field cells.

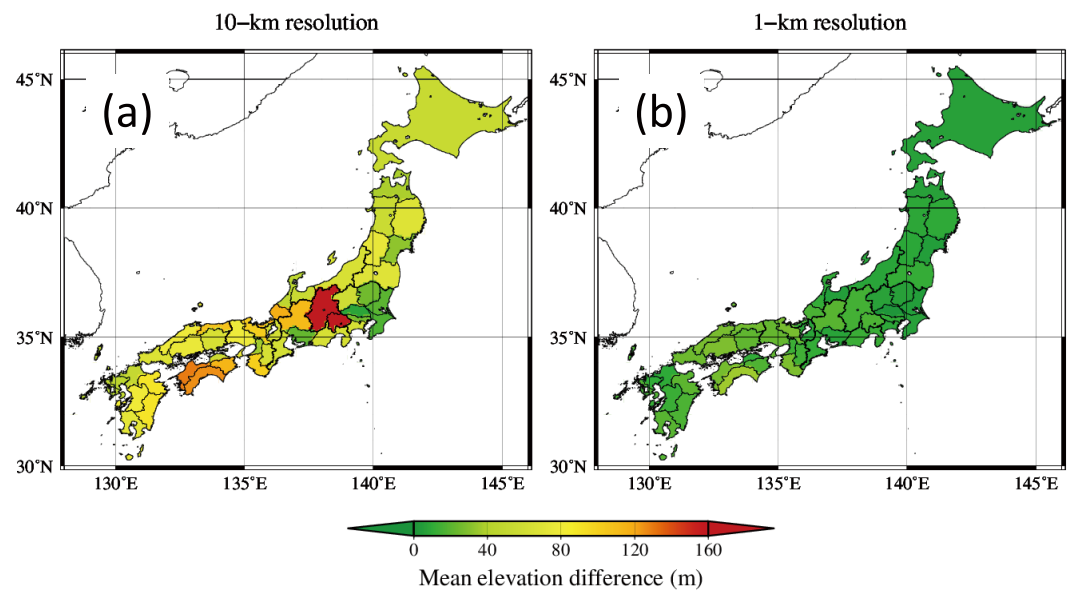

Fig. 3. The mean elevation differences between the grid cell and the internal sub-grid cells with a paddy field, averaged by prefecture (a) at $10-\mathrm{km}$ resolution and (b) at $1-\mathrm{km}$ resolution. Values are positive if the elevation of the grid cell is larger than the mean elevation for internal paddy-field cells.

period from 1981 to 2000 based on four temperature scenarios (a baseline scenario with no change and increases of 1,2 , and $3{ }^{\circ} \mathrm{C}$ ). To assess the effects of the input data's spatial resolution on the yield simulation under baseline climatic conditions, we averaged the estimated yields from 1981 to 2000 in each grid cell, and subsequently calculated the differences between the yield estimated using input data with $10-\mathrm{km}$ or $1-\mathrm{km}$ resolution and the yield estimated using input data with $100-\mathrm{m}$ resolution.

Figures $4 \mathrm{a}$ and $4 \mathrm{~b}$, respectively, show the spatial distributions of the yield differences with $10-\mathrm{km}$ and $1-\mathrm{km}$ resolutions calculated using the baseline input data. Figs. $4 \mathrm{c}$ and $4 \mathrm{~d}$, respectively, show the corresponding results with a $3{ }^{\circ} \mathrm{C}$ temperature increase. For the data with $10-\mathrm{km}$ resolution, the yield differences were remarkably large at grid cells with a large elevation difference (Fig. 2a), and under baseline climate conditions, the sign of the difference ( + for values greater than the $100-\mathrm{m}$ yield and - for values less than the $100-\mathrm{m}$ yield) depended on the location (Fig. 4a). The differences were negative in the northeastern half of Japan and in the high-elevation areas in the central part, where the climate is relatively cool, whereas the difference was positive in the southwestern half of Japan, including the low-elevation area in the central part, where the climate is relatively warm (Fig. 4a). This pattern indicated that the negative temperature bias led to underestimation of the yield when the climate was relatively cool, but led to overestimation of the yield when the climate was relatively warm. Furthermore, the yield differences were positive in almost all areas when the temperature increased by $3{ }^{\circ} \mathrm{C}$ (Fig. $4 \mathrm{c}$ ), which suggests that the negative temperature bias may increase the estimated yield even in areas with a relatively cool climate under the baseline conditions. At 1-km resolution (Fig. $4 \mathrm{~b}$ for the baseline input data, and $4 \mathrm{~d}$ for the increased temperatures, respectively), the spatial patterns of the yield differences were similar to those with $10-\mathrm{km}$ resolution, although the values of the yield differences were smaller than those at $10-\mathrm{km}$ resolution.

Figure 5 shows the changes in the distribution of the yield differences under the four temperature increase scenarios for each spatial resolution for the whole country (Fig. 5a), the Kanto 

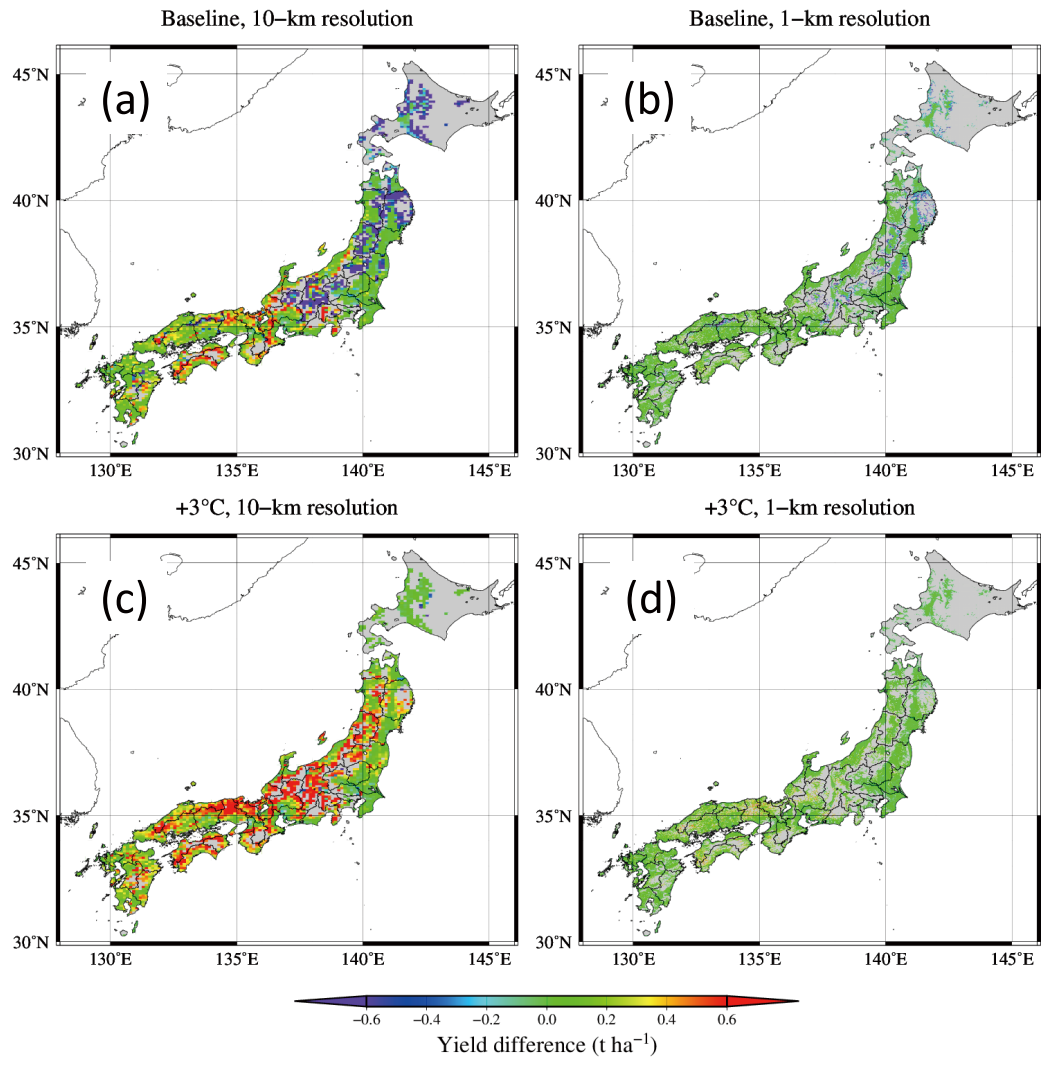

Fig. 4. The spatial distribution of the differences between the yield estimated using input data with each spatial resolution and those estimated using data with $100-\mathrm{m}$ resolution; under the baseline scenario for (a) $10-\mathrm{km}$ resolution and (b) 1-km resolution; and under the $+3{ }^{\circ} \mathrm{C}$ scenario for (c) 10-km resolution and (d) 1-km resolution.

region (which has only moderately complex terrain; Fig. 5b), and the Koshin region (which has complex terrain; Fig. 5c). The distributions for the whole country (Fig. 5a) and for Kanto region (Fig. 5b) were similar, with only small ranges in the distribution in all four temperature scenarios and relatively small differences between $10-\mathrm{km}$ and $1-\mathrm{km}$ resolutions. In contrast, the data for Koshin region (Fig. 5c) showed a much wider distribution at $10-\mathrm{km}$ resolution; the range of the distribution for the yield differences (from the 5 th to the 95 th percentile) ranged from $-4.92 \mathrm{t} \mathrm{ha}^{-1}$ to $+0.65 \mathrm{t} \mathrm{ha}^{-1}$ and averaged $-0.81 \mathrm{t} \mathrm{ha}^{-1}$, representing underestimation by $11.5 \%$ in the baseline scenario. The range became smaller and shifted to positive values as the temperature increased; the range decreased to between -0.12 and $+1.40 \mathrm{tha}^{-1}$ and averaged $+0.35 \mathrm{t} \mathrm{ha}^{-1}$, representing overestimation by $5.4 \%$ in the $3{ }^{\circ} \mathrm{C}$ scenario. On the other hand, the range of the distribution was small in all four temperature scenarios at $1-\mathrm{km}$ resolution (varying within $\pm 0.5 \mathrm{t} \mathrm{ha}^{-1}$ ).

\section{Discussion}

In general, the gridded meteorological data that are used to drive large-area impact assessment models are developed by interpolating observed meteorological data based on the mean elevation of the grid cells (e.g. Seino, 1993; Ohno et al., 2016). Thus, the representativeness of the meteorological data decreases as the elevation differences increase between the mean for an entire grid cell and the mean for crop fields contained in the grid cell. In an area with complex topography, such as coastal areas, small basins, and mountainous areas, these elevation
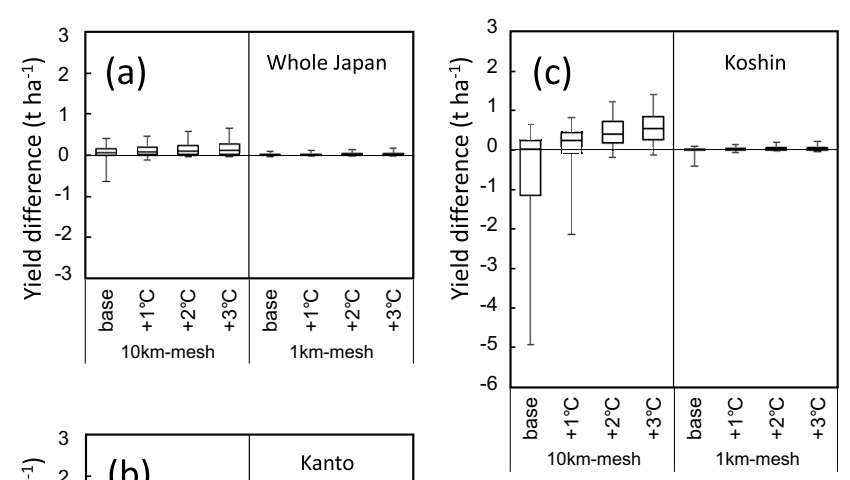

Fig. 5. Comparison of the distributions of yield differences compared with the $100-\mathrm{m}$ resolution data for the four temperature increase scenarios (base $=$ the baseline scenario with no increase). Results are presented for $10-\mathrm{km}$ and $1-\mathrm{km}$ spatial resolutions for (a) the whole Japan, (b) the Kanto region (which has moderately complex terrain), and (c) the Koshin region (which has complex terrain). Box plots show the 75th and 25th percentiles, dark horizontal lines represent the median, and whiskers represent the 95th and 5th percentiles. 
differences can be large (Kim et al., 2015; Zhao et al., 2015). Because temperatures decrease with increasing elevation, this can introduce a temperature bias. In the case of Japanese paddy fields, large elevation differences could lead to large systematic bias in temperatures throughout Japan, except in some plains areas in the 10-km resolution dataset, as described in Section 3.1.

To clarify the regional distribution of the elevation differences that are associated with the anticipated temperature bias, we classified the elevation differences into classes at 80-m intervals, and calculated the proportion of each class in each region at $10-\mathrm{km}$ and $1-\mathrm{km}$ resolutions (Figs. $6 \mathrm{a}$ and $6 \mathrm{~b}$, respectively). Note that we
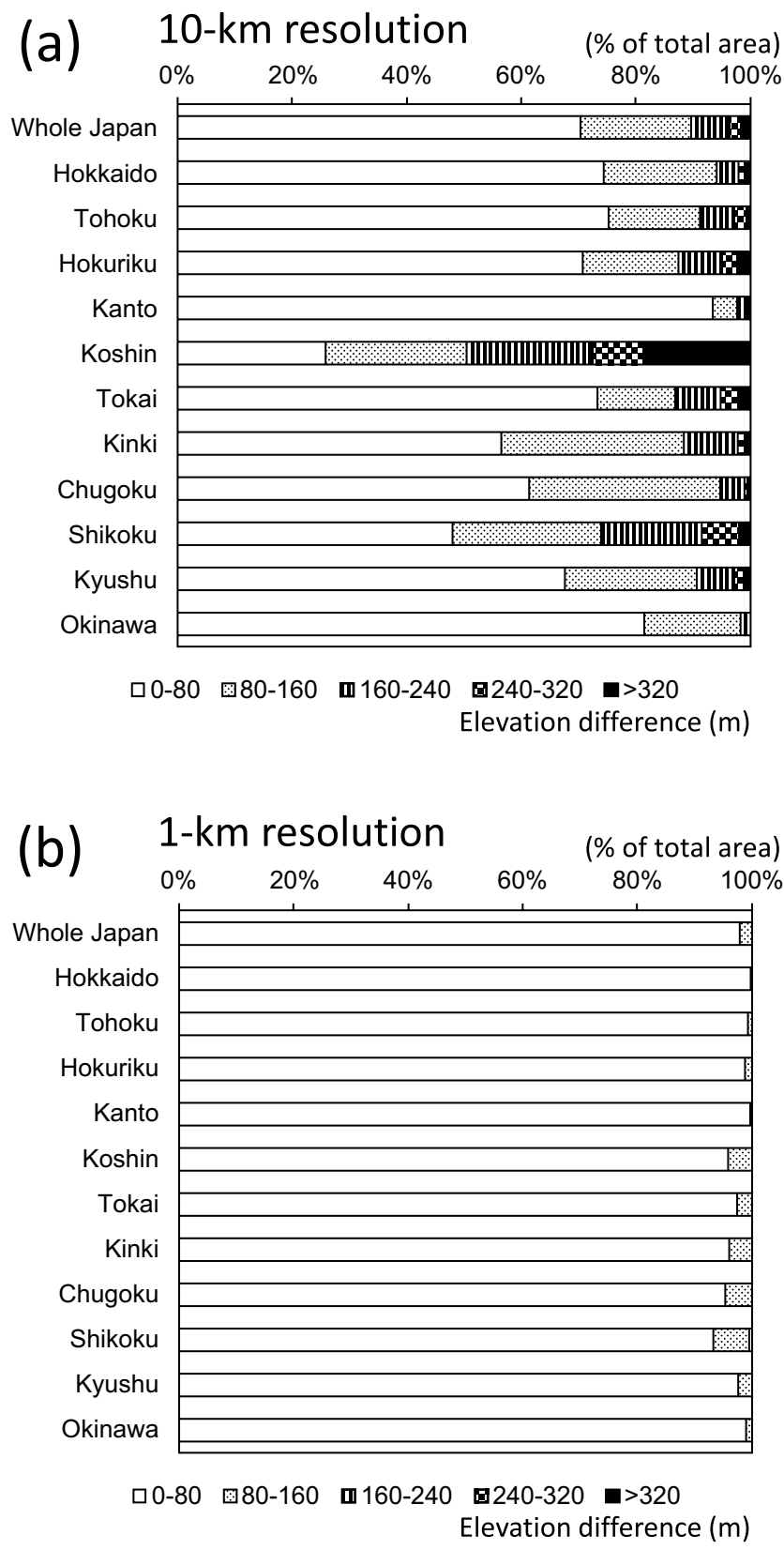

Fig. 6. The proportions of the area of each grid cell within five 80-m elevation difference classes for all of Japan and in each region for (a) 10-km resolution and (b) 1-km resolution. (Note that the elevation increase of $80 \mathrm{~m}$ is approximately equivalent to a temperature decrease of $0.5^{\circ} \mathrm{C}$ based on the common temperature lapse rate of $-0.0065^{\circ} \mathrm{C} \mathrm{m}^{-1}$ ). chose an elevation interval of $80 \mathrm{~m}$ because this is approximately equivalent to a temperature decrease of $0.5^{\circ} \mathrm{C}$ based on the common temperature lapse rate $\left(-0.0065{ }^{\circ} \mathrm{C} \mathrm{m}^{-1}\right)$. At $10-\mathrm{km}$ resolution (Fig. 6a), the proportion of the elevation differences that were $>80 \mathrm{~m}$ was larger than $20 \%$ in all regions except the Kanto region, which is dominated by plains and relatively simple terrain. In contrast, the Koshin and Shikoku regions have relatively complex terrain, so the proportions of the area with an elevation difference $>160 \mathrm{~m}$, which is equivalent to a temperature bias of $-1{ }^{\circ} \mathrm{C}$, were approximately $50 \%$ and $30 \%$, respectively. Furthermore, the proportion of the area with an elevation difference $>320 \mathrm{~m}$ (equivalent to a temperature bias of $-2{ }^{\circ} \mathrm{C}$ ) was almost $20 \%$ in the Koshin region. At 1-km resolution (Fig. 6b), in contrast, the proportion of the area with an elevation difference $>80 \mathrm{~m}$ was small in almost all regions; the largest proportion was in the Shikoku region, but the proportion was less than $10 \%$.

The spatial distributions of the yield differences (Fig. 4a-d) were strongly related to the elevation differences described above. At $10-\mathrm{km}$ resolution, the most remarkable finding was that the negative yield differences under the baseline climate conditions in some grid cells with a large elevation difference in central to northern part of Japan (Fig. 4a) changed to positive values when the temperature increased by $3{ }^{\circ} \mathrm{C}$ (Fig. 4c). Also, as shown in Fig. 5c, the distribution for the yield differences within the Koshin region (which has complex terrain) was largely negatively biased at $10-\mathrm{km}$ resolution, but this bias nearly disappeared at $1-\mathrm{km}$ resolution. The response of crop yield to changes in meteorological conditions is typically considered to be nonlinear (Lobell et al., 2011; Rezaei et al., 2015). The increase or decrease in yield due to a negative temperature bias depends on whether the temperature in cultivation period is above or below the optimum temperature. In the case of the Koshin region, the yield decreased due to the negative temperature bias because it was below the optimum temperature under the base temperature condition, and increased due to the negative temperature bias because it was above the optimum temperature under the $+3{ }^{\circ} \mathrm{C}$ condition. Rice exhibits strong sensitivity to temperature (Yoshida, 1973), so its yield response to the temperature bias differed greatly among the locations.

Our results suggest that the uncertainty in the simulated yield is so large that assessments of the impact of climate change on rice productivity compared with baseline conditions may be seriously affected. Fig. 7 shows the regional mean yield simulated under the baseline climate conditions and in the scenario with a $3{ }^{\circ} \mathrm{C}$ temperature increase for the three spatial resolutions for all of Japan (Fig. 7a) and within the Koshin region (Fig. 7b). In the Koshin region, which has complex topography, the mean yield increased in the $3{ }^{\circ} \mathrm{C}$ scenario at $10-\mathrm{km}$ resolution, although the mean yield decreased under this temperature increase at $100-\mathrm{m}$ and $1-\mathrm{km}$ resolutions. This change resulted from underestimation of yield under the baseline climate conditions and overestimation of yield due to the temperature increase at $10-\mathrm{km}$ resolution. This result suggests that if we can assume that the outputs at $100-\mathrm{m}$ resolution represent the true value, $10-\mathrm{km}$ resolution was too coarse to obtain accurate results in regional assessments of the impact of climate change on rice productivity in the Koshin region. On the other hand, the yield 
in the $3{ }^{\circ} \mathrm{C}$ scenario was less than that in the baseline scenario at all spatial resolutions for Japan as a whole (Fig. 7a), suggesting that $10-\mathrm{km}$ resolution may provide acceptable accuracy for national-scale assessments. In recent years, the development of geographic and meteorological information has progressed, and precise impact assessment using high-resolution input data has become possible. Meanwhile, as large-scale and long-term impact assessment of climate change has been required, the use of low-resolution data (here, $10 \mathrm{~km}$ ) can be effective from the viewpoint of reducing the computational load, depending on the target location and spatial scale. Also, it seems to be expected that the temperature bias of low-resolution meteorological data can be eliminated by using the pre-determined differences between the mean elevation for entire grid and the mean elevation for target area within the grid and the lapse rate.

Our findings suggested that the optimal spatial resolution depends strongly on the complexity of the terrain within the area of interest and on the size of the area covered by the analysis. Moreover, the magnitude of the effect of the spatial resolution on the yield differed among locations even with comparable topographic conditions. In this study, we only considered two spatial resolutions $(10-\mathrm{km}$ and $1-\mathrm{km})$ to determine their effect on yield estimation, whereas previous studies considered a range of spatial resolutions including larger than 10-km (van Bussel et al., 2011; Angulo et al., 2013; Rezaei et al., 2015; Zhao et al., 2015;
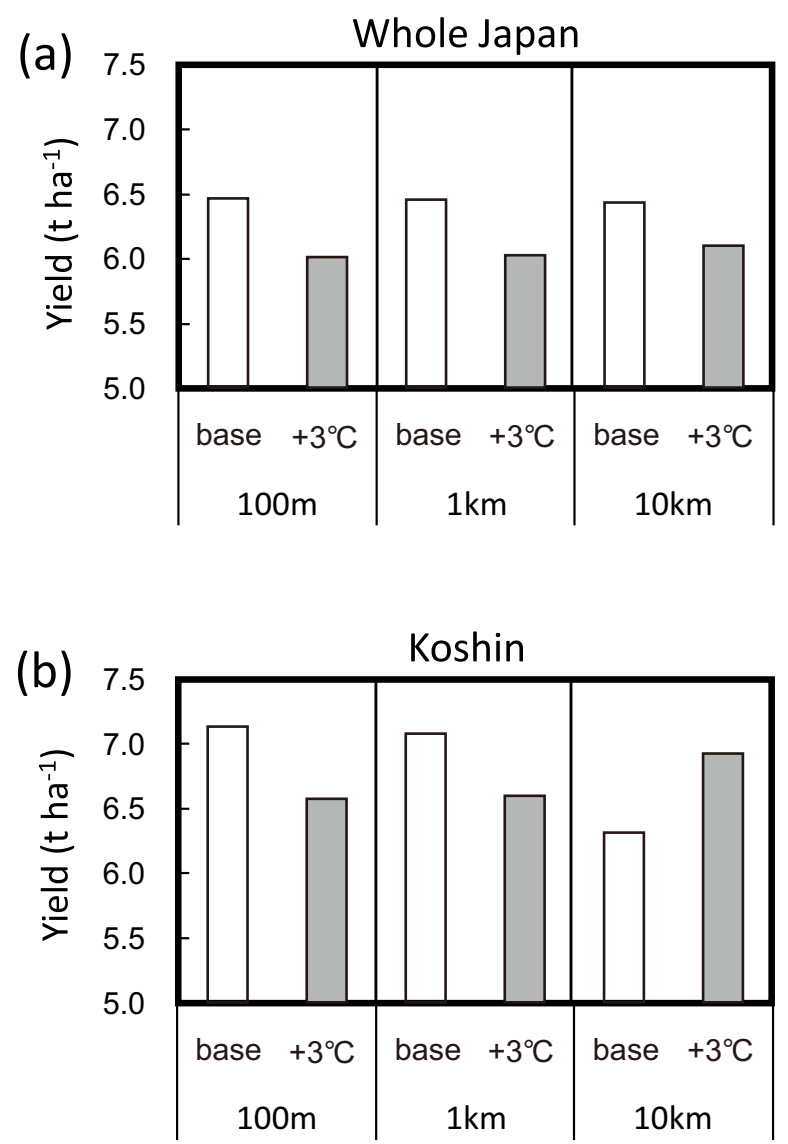

Fig. 7. Comparison of the regional mean simulated yield under the baseline climate conditions and in the scenario with a $3{ }^{\circ} \mathrm{C}$ temperature increase for the three spatial resolutions for (a) whole Japan and (b) Koshin region (which has complex terrain).
Hoffmann et al., 2016). Our results nonetheless indicated that assessments with a resolution coarser than $10-\mathrm{km}$ seem unlikely to be suitable for Japanese crops, particularly for crops such as rice that are sensitive to temperature changes and particularly at a national scale. In this study, we evaluated the appropriate spatial resolution for assessing the effects of climate change on Japanese rice productivity using only a single crop model. Some previous studies found that the effect on yield simulation caused by differences in the model used was larger than the effect of differences in spatial resolution of the input data (Angulo et al., 2013; Hoffmann et al., 2016). Also, the impact of uncertainty on crop yield simulation could differ by crop models depending on the sensitivity to weather input variables (Kim and Yoo, 2015). Thus, our future research should extend the present results to include additional models.

\section{Conclusions}

In this study, we evaluated the effect of the spatial resolution of the input data on rice yield in Japan by comparing the yields calculated with spatial resolutions of 10 and $1 \mathrm{~km}$ with the yield calculated using a 100-m resolution, which we considered to represent the true value. Our analysis revealed a systematic temperature bias in the input data due to elevation differences between the mean for an entire grid cell and the mean for cells that assigned to a paddy field in the grid cell. The yield differences at $10-\mathrm{km}$ resolution were larger than those at $1-\mathrm{km}$ resolution in areas with complex terrain, but the differences were much smaller in areas with smooth terrain. In regions with extremely complex terrain, regional mean yields were underestimated under the baseline climatic conditions but overestimated in the scenarios with a temperature increase at $10-\mathrm{km}$ resolution. This difference may be a major cause of uncertainty in climate change assessments at a regional scale.

Our results indicated that to assess the impact of climate change on rice productivity in Japan, a high spatial resolution (here, 1-km resolution) should be used for regional assessments on the areas where terrain is complex whereas the coarser spatial resolution (here, $10-\mathrm{km}$ resolution) may be effective for assessments on the entire country or the areas where terrain is not complex, which has an advantage in terms of efficient use of computing resources.

\section{Acknowledgments}

This study was supported as a part of research projects funded by the Ministry of the Environment ("Regional Adaptation Consortium Project"), the Ministry of Agriculture, Forestry and Fisheries ("Development of Technologies for Mitigation and Adaptation to Climate Change in Agriculture, Forestry and Fisheries"), and the Ministry of Education, Culture, Sports, Science and Technology ("Social Implementation Program on Climate Change Adaptation Technology", SI-CAT).

\section{References}

Angulo C, Rötter R, Trnka M, Pirttioja N, Gaiser T, Hlavinka P, Ewert F, 2013: Characteristic 'fingerprints' of crop model responses to weather input data at different spatial resolutions. European Journal of Agronomy 49, 104-114. 
DOI:10.1016/j.eja.2013.04.003.

Daly C, 2006: Guidelines for assessing the suitability of spatial climate data sets. Int. J. Climatol. 26(6), 707-721.

Fukui S, Ishigooka Y, Kuwagata T, Hasegawa T, 2015: A methodology for estimating phenological parameters of rice cultivars utilizing data from common variety trials. Journal of Agricultural Meteorology 71(2), 77-89.

Geographical Survey Institute Japan, 1997: Digital map $50 \mathrm{~m}$ grid (elevation). Technical report, Geospatial Information Authority of Japan. NIPPON-III.

Hansen J, Jones J, 2000: Scaling-up crop models for climate variability applications. Agric. Syst. 65, 43-72.

Hasegawa T, Horie T, 1997: Modelling the effect of nitrogen on rice growth and development. In Applications of systems approaches at the field level. (ed. by Kropff MJ, Teng PS, Aggarwal PK, Bouma J, Bouman BAM, Jones JW, van Laar HH). Kluwer, Dordrecht, pp. 243-257.

Hasegawa T, Sakai H, Tokida T, Usui Y, Yoshimoto M, Fukuoka M, Nakamura H, Shimono H, Okada M, Hatfield JL, Fleisher D, 2016: Rice free-air carbon dioxide enrichment studies to improve assessment of climate change effects on rice agriculture. In Improving Modeling Tools to Assess Climate Change Effects on Crop Response (ed. by Hatfield JL, Fleisher D). American Society of Agronomy, Madison, WI USA. Doi:10.2134/advagricsystmode17.2014.0015.

Hayashi Y, Ishigooka Y, Yokozawa H, Toritani H, Goto S, 2001: Impacts of global warming on potential characteristics of rice cultivation in Japan. Global Environmental Research 6, 141-148 (in Japanese).

Hoffmann H, Zhao G, van Bussel L, Enders A, Specka X, Sosa C, Yeluripati J, Tao F, Constantin J, Raynal H, Teixeira E, Grosz B, Doro L, Zhao Z, Wang E, Nendel C, Kersebaum K, Haas E, Kiese R, Klatt S, Eckersten H, Vanuytrecht E, Kuhnert M, Lewan E, Rötter R, Roggero P, Wallach D, Cammarano D, Asseng S, Krauss G, Siebert S, Gaiser T, Ewert F, 2016: Variability of effects of spatial climate data aggregation on regional yield simulation by crop models. Climate Research 65, 53-69.

Horie T, Nakagawa H, Ohnishi M, Nakano J, 1995: Rice production in Japan under current and future climates. In Modeling the Impact of Climate Change on Rice in Asia. (ed. by Matthews RB, Kropff MJ, Bachelet D, van Laar HH). CAB International, Oxon, pp.143-164.

Iizumi T, Hori ME, Yokozawa M, Nakagawa H, Hayashi Y, Kimura F, 2006: Impact of global warming on rice production in Japan based on five coupled atmosphere-ocean GCMs. SOLA 2, 156-159.

Iizumi T, Yokozawa M, Nishimori M, 2011: Probabilistic evaluation of climate change impacts on paddy rice productivity in Japan. Climatic Change 107, 391-415.

Ishigooka Y, Fukui S, Hasegawa T, Kuwagata T, Nishimori M, Kondo M, 2017: Large-scale evaluation of the effects of adaptation to climate change by shifting transplanting date on rice production and quality in Japan. Journal of Agricultural Meteorology 73(4), 156-173.

Japan Meteorological Agency (JMA), 2002: Mesh Climatic Data 2000. Japan Meteorological Business Support Center, Tokyo.

Kim K, Yoo B, 2015: Comparison of regional climate scenario data by a spatial resolution for the impact assessment of the uncertainty associated with meteorological inputs data on crop yield simulations in Korea. J. Crop. Sci. 18(4), 249-255.

Kim J, Sang W, Shin P, Cho H, Seo M, Yoo B, Kim K, 2015:
Evaluation of regional climate scenario data for impact assessment of climate change on rice productivity in Korea. $J$. Crop. Sci. 18(4), 257-264.

Kuwagata T, Ishigooka Y, Fukuoka M, Yoshimoto M, Hasegawa T, Usui Y, Sekiguchi T, 2014: Temperature Difference between Meteorological Station and Nearby Farmland -Case Study for Kumagaya City in Japan-. SOLA 10, 45-49.

Lobell DB, Bänziger M, Magorokosho C, Vivek B, 2011: Nonlinear heat effects on African maize as evidenced by historical yield trials. Nat. Clim. Change 1, 42-45.

Ministry of Agriculture, Forestry and Fisheries (MAFF), 2018: Crop statistics. Ministry of Agriculture, Forestry and Fisheries, Tokyo.

Ohno H, Sasaki K, Ohara G, Nakazono K, 2016: Development of grid square air temperature and precipitation data compiled from observed, forecasted, and climatic normal data. Climate in Biosphere 16, 71-79 (in Japanese with English abstract).

Olesen JE, Bocher PK, Jensen T, 2000: Comparison of scales of climate and soil data for aggregating simulated yields of winter wheat in Denmark. Agric. Ecosyst. Environ. 82(1-3), 213-228.

Rezaei EE, Siebert S, Ewert F, 2015: Impact of data resolution on heat and drought stress simulated for winter wheat in Germany. European Journal of Agronomy 65, 69-82.

Rosenzweig CJ, Deryng D, Ruane AC, Müller C, Arneth A, Boote KJ, Folberth C, Glotter M, Khabarov N, Neumann K, Piontek F, Pugh TA, Schmid E, Stehfest E, Yang H, Jones JW, 2014: Assessing agricultural risks of climate change in the 21 st century in a global gridded crop model intercomparison. PNAS 111(9), 3268-3273.

Seino H, 1993: An estimation of distribution of meteorological elements using GIS and AMeDAS data. Journal of Agricultural Meteorology 48, 379-383 (in Japanese with English abstract).

Seino H, 1997: Global climate change and food production in Japan. Journal of Agricultural Meteorology 52(5), 367-376.

van Bussel L, Ewert F, Leffelaar P, 2011: Effects of data aggregation on simulations of crop phenology. Agric. Ecosyst. Environ. 142, 75-84.

van Bussel LGJ, Ewert F, Zhao G, Hoffmann H, Enders A, Wallach D, Asseng S, Baigorria GA, Basso B, Biernath C, Cammarano D, Chryssanthacopoulos J, Constantin J, Elliott J, Glotter M, Heinlein F, Kersebaum KC, Klein C, Nendel C, Priesack E, Raynal H, Romero CC, Rotter RP, Specka X, Tao F, 2016: Spatial sampling of weather data for regional crop yield simulations. Agricultural and Forest Meteorology 220, 101-115.

Yokozawa M, Iizumi T, Okada M, 2009: Large scale projection of climate change impacts on variability in rice yield in Japan. Global Environmental Research 14, 199-206 (in Japanese).

Yonemura S, Yajima M, Sakai H, Morokuma M, 1998: Estimate of rice yield of Japan under the conditions with elevated $\mathrm{CO}_{2}$ and increased temperature by using third mesh climate data. Journal of Agricultural Meteorology 54(3), 235-245 (in Japanese with English abstract).

Yoshida R, Fukui S, Shimada T, Hasegawa T, Ishigooka Y, Yakayabu I, Iwasaki T, 2015: Adaptation of rice to climate change through a cultivar-based simulation: a possible cultivar shift in eastern Japan. Climate Research 64, 275-290.

Yoshida S, 1973: Effects of temperature on growth of the rice plant (Oryza sativa L.) in a controlled environment. Soil Science and Plant Nutrition 19(4), 299-310.

Zhao G, Siebert S, Enders A, Rezaei EE, Yan C, Ewert F, 2015: Demand for multi-scale weather data for regional crop modeling. Agricultural and Forest Meteorology 200, 156-171. 